\title{
Effect of Different Habitats on Richness of Land Snail Fauna in Knuckles Forest Range in Sri Lanka
}

\author{
Karunarathna K.A.N.K. ${ }^{{ }^{*}}$, Wijekoon . $^{2}$ and Ranawana K.B. ${ }^{3}$ \\ ${ }^{1}$ Department of Mathematics, Faculty of Science, Eastern University, Chenkalady-30350, Sri Lanka. \\ ${ }^{2}$ Department of Statistics and Com. Science, Faculty of Science, University of Peradeniya, \\ Peradeniya, Sri Lanka. \\ ${ }^{3}$ Department of Zoology, Faculty of Science, University of Peradeniya, Peradeniya, Sri Lanka. \\ *nkkarunarathna@gmail.com
}

\begin{abstract}
Richness of land snail fauna is not uniform over the all regions in the country and several factors are believed to be affected on richness of land snail fauna. This study aimed to investigate the effects of different habitats on the richness of land snail fauna in Knuckles forest range.

A sample of 115 plots of size $100 \times 2 \mathrm{~m}^{2}$ was considered. These plots were selected covering seven different types of habitats in Knuckles forest: montane forest, submontane forest, montane zone cardamom forest, submontane zone cardamom forest, submontane zone grasslands, intermediate zone forest, and intermediate zone homegardens. Plots from each habitat were selected based on the convenience for sampling. Inside each plot, number of individuals belonging to each species was recorded as the responses.

Multivariate analysis of variance (MANOVA) technique was used to test the dependence of number of individuals and number of species on habitats. Results of MANOVA were tested by applying univariate analysis of variation (ANOVA) technique for each response separately to confirm the results of MANOVA. For the above analysis, log transformed data of number of individuals and species were used as the responses. Finally, Chi-Square test was used to confirm the dependence of land snail fauna on habitats.

Results of statistical analysis confirmed that the richness of land snail fauna in the all habitats considered is not significantly different. Habitat-wise variation of richness of land snail fauna can not be observed in this region. This implies that richness of land snail fauna in Knuckles forest range does not vary with different habitats considered.
\end{abstract}

Keywords: Dependence, Snail fauna, Richness 